\title{
]jfis
}

\section{Development and Analysis of Models for Assessing Predicted Mean Vote Using Intelligent Technologies}

\author{
L. Zh. Sansyzbay ${ }^{1}$, B. B. Orazbayev ${ }^{1}$ and W. Wójcik ${ }^{2}$ \\ ${ }^{1}$ Faculty of Information Technology, Department of System Analysis and Control, L. N. Gumilyov Eurasian \\ National University, Nur-Sultan, Kazakhstan \\ ${ }^{2}$ Lublin University of Technology, Lublin, Poland
}

\section{Abstract}

One of the approaches toward determining the degree of microclimate comfort is measuring its individual components: temperature, air velocity, relative humidity, and air quality. A significant disadvantage of this approach is the neglect of the mutual influence of microclimate parameters on each other. To improve the accuracy of determining microclimate comfort, it is necessary to use a complex predicted mean vote (PMV) indicator. The PMV equation is complex and computationally consuming; simplified solutions can be obtained using Fanger's diagrams, Excel calculation programs, and specialized computer applications. With the development of technology, intelligent microclimate systems are gaining popularity. In this article, for selecting one of the most effective intelligent technologies, models have been developed for assessing the PMV indicator using the frameworks of fuzzy logic and neural networks. The data obtained using the calculation program of the researchers of the Federal State Unitary Enterprise Research Institute (Russia) were used as input parameters for the models' development. The program's performance was validated against the PMV parameter values in the ISO 7730:2005 standard, and a good agreement was found. The PMV index values produced by the considered models were compared to the values calculated using the program, to determine the operability and efficiency of the developed models. Our analysis suggests that neural networks perform better on the assessment of thermal comfort, compared with fuzzy systems.

Keywords: Microclimate parameters, ISO 7730:2005 standard, PMV thermal comfort index, Fanger's thermal comfort model, Fuzzy logic, Neural networks, MATLAB software package

\section{Introduction}

Humans in modern societies spend a considerable amount of time indoors. Unfavorable indoor climate results in low labor productivity and frequent illnesses among workers. Specifically, [1] presents data on the consequences of the lack of a comfortable microclimate indoors, as well as the corresponding indicators of financial losses. Partially, this problem arises as a result of poor-quality microclimate regulation in buildings, or as a result of an incorrect assessment of the degree of thermal comfort in the created microclimate.

Intelligent technologies, such as fuzzy logic, neural networks, genetic algorithms, and 
multi-agent systems, have been used to improve the quality of microclimate regulation [2-10] and assess the degree of thermal comfort [11-13].

The authors [11] describes an algorithm for calculating the predicted mean vote (PMV) index, developed using artificial neural networks (ANNs). In that study, an ANN was trained using only one input parameter, namely the air temperature. The authors of the study have considered ANNs with different numbers of neurons in the first layer, and used different learning functions of the neural network to determine the optimal structure of the neural network. Based on this, the authors of the study established that the trainlm function with 100 neurons in the first layer yielded the fastest training and the smallest absolute error.

The adequacy of the developed neural network was determined based on comparative analysis of the PMV values at its output with the values of the calculation program developed in accordance with the regulations of the ISO 7730:2005 standard. The analysis has shown that neural networks can be used as an alternative tool for determining the thermal comfort index of a room. The authors of that study suggested to focus on modifying their neural network in such a way that, when training the network using other parameters, the components of the PMV calculation equation will be used as input data. Practical applications of the developed model have not been given.

The study [12] proposed to use a neural network-based PMV model based on practical measurements, for calculating the human thermal comfort index. The model measured the wetbulb temperature and globe thermometer temperature instead of the relative humidity and mean radiant temperature. A feedforward neural network was used for modeling the impact of the air temperature, wet bulb temperature, globe thermometer temperature, air velocity, clothing insulation, and human activity on the PMV index. An experiment was conducted, based on the given air-conditioned office space, to demonstrate the effectiveness of the proposed technique. The results obtained by the authors showed a good agreement between the thermal comfort index calculated using the neural network model in real time and the thermal comfort index calculated using Fanger's model.

In [13], using a fuzzy logic apparatus, a model has been developed to assess the thermal comfort of the microclimate of residential buildings located in tropical climate regions. A survey was conducted among residents, for collecting initial data. Overall, there were 538 samples from Singapore and 525 from Indonesia. The data were collected in extensive field research, covering the rainy and dry seasons of 2000-2002. Initial data analysis was performed as probit analysis, using the SPSS version 10 software (SPSS Inc., Chicago, IL, USA). Probit curves were obtained using the analysis software, and were used in the fuzzification stage of input variables. After analyzing the initial data in [13], the authors conducted modeling studies. The stages of fuzzification and defuzzification have been described in detail as well as the stage of developing a rule base.

The reliability of the developed model was checked using a test sample (200 values). The model's outputs were compared with the actual values in the polling stage. The correlation coefficient was 0.8553 . Thus, it was concluded that the model can be used for predicting the thermal comfort in naturally ventilated buildings located in the tropical climate zone. As a next step, the authors planned to develop models for assessing thermal comfort in administrative buildings, such as schools and offices.

Our main objective is the development of an energy-saving intelligent microclimate system. One of the components of this system is a model for estimating the PMV indicator. In the present study, we develop two models, using fuzzy logic and neural networks, to determine a more effective technology for use in the development of the above model.

Model development was done in the MATLAB environment. While analyzing the works of foreign and domestic authors, the MATLAB modeling environment was identified as the most suitable tool owing to its ease of use, good performance, and the availability of a large number of methodological materials regarding its use [14].

Despite the huge number of works in the field of microclimate research, devoted to predicting and determining the thermal comfort index, no studies reported comparative analyses of various approaches (different models).

In this regard, this article provides a comparative analysis of the developed models, the ISO 7730:2005 standard, and existing software products, for determining the possibility of using models as an adequate tool for evaluating thermal comfort in a room.

\section{Theory and Methods}

\subsection{Aim and Objectives of the Study}

The aim of this work is to develop fuzzy logic and neural network-based models for assessing the thermal comfort in a room, conduct a comparative analysis, and determine the performance and efficiency of the developed models by com- 
paring the PMV values yielded by these models with the values calculated using the program.

The following research tasks were defined and successfully addressed in the present work:

- Study Fanger's thermal comfort model;

- Investigate ways of determining the PMV thermal comfort index;

- Prepare initial data required for modeling;

- Validate the calculation program;

- Develop fuzzy logic and neural network-based models;

- Determine the effectiveness of the developed models by comparative analysis of the values produced by the models with the values produced by the calculation program.

\subsection{Fanger's Thermal Comfort Model}

To assess the thermal comfort of the microclimate in buildings in foreign countries, the PMV index is used, which is regulated by the standard ISO 7730:2005 "Ergonomics of the thermal environment - Analytical determination and interpretation of thermal comfort using calculation of the PMV and PPD indices and local thermal comfort criteria" [15].

The ISO 7730:2005 standard is based on Fanger's thermal comfort model [16, 17], which combines four parameters of the indoor microclimate (indoor air temperature, relative air velocity, mean radiant temperature, relative humidity) and two human factors (clothing and physical activity) into a complex PMV index, which allows predicting thermal comfort for a group of people in a room on a 7-point scale based on the balance of the human body temperature [15](Table 1).

Table 1. Seven-point scale of temperature sensitivity

\begin{tabular}{cc}
\hline Score in points & Thermal sensation \\
\hline+3 & Hot \\
+2 & Warm \\
+1 & Slightly warm \\
0 & Neutral \\
-1 & Slightly cool \\
-2 & Cool \\
-3 & Cold \\
\hline
\end{tabular}

PMV index and its components are determined by the following Equations 14 [4][15]:

$$
\begin{aligned}
& P M V \\
& =[0.303 \cdot \exp (-0.036 \cdot M)+0.028] \\
& \cdot\left\{(M-W)-3.05 \cdot 10^{-3} \cdot[5733-6.99 \cdot(M-W)\right. \\
& \left.-p_{a}\right]-0.42 \cdot[(M-W)-58.15]-1.7 \cdot 10^{-5} \\
& \cdot M \cdot\left(5867-p_{a}\right)-0.0014 \cdot M \cdot\left(34-t_{a}\right) \\
& -3.96 \cdot 10^{-8} \cdot f_{c l} \cdot\left[\left(t_{c l}+273\right)^{4}-\left(t_{r}+273\right)^{4}\right] \\
& \left.-f_{c l} \cdot h_{c} \cdot\left(t_{c l}-t_{a}\right)\right\} \text {, } \\
& t_{c l}=35.7-0.028 \cdot(M-W)-I_{c l} \cdot\left\{3.96 \cdot 10^{-8} \cdot f_{c l}\right. \\
& \left.\cdot\left[\left(t_{c l}+273\right)^{4}-\left(t_{r}+273\right)^{4}\right]+f_{c l} \cdot h_{c} \cdot\left(t_{c l}-t_{a}\right)\right\}, \\
& h_{c}=\left\{\begin{array}{c}
2.38 \cdot\left|t_{c l}-t_{a}\right|^{0.25} \text { for } 2.38 \cdot\left|t_{c l}-t_{a}\right|^{0.25} \\
>12.1 \cdot \sqrt{v_{a r}}, \\
12.1 \cdot \sqrt{v_{a r}} \text { for } 2.38 \cdot\left|t_{c l}-t_{a}\right|^{0.25} \\
<12.1 \cdot \sqrt{v_{a r}},
\end{array}\right. \\
& f_{c l}=\left\{\begin{array}{l}
1.00+1.290 I_{c l} \text { for } I_{c l} \leq 0.078 m^{2} \cdot K / W, \\
1.05+0.645 I_{c l} \text { for } I_{c l}>0.078 m^{2} \cdot K / W
\end{array}\right.
\end{aligned}
$$

where

$M$ is the metabolic rate, $\mathrm{W} / \mathrm{m}^{2}$;

$W$ is the effective mechanical power, $\mathrm{W} / \mathrm{m}^{2}$;

$I_{c l}$ is the clothing insulation, $\mathrm{m}^{2} \mathrm{~K} / \mathrm{W}$;

$f_{c l}$ is the clothing surface area factor,

$t_{a}$ is the air temperature in the room, ${ }^{\circ} \mathrm{C}$;

$t_{r}$ is the mean radiant temperature, ${ }^{\circ} \mathrm{C}$,

$v_{a r}$ is the relative air velocity, $\mathrm{m} / \mathrm{s}$;

$p_{a}$ is water vapor partial pressure, $\mathrm{Pa}$;

$h_{c}$ is the convective heat transfer coefficient, $\mathrm{W} /\left(\mathrm{m}^{2} \mathrm{~K}\right)$;

$t_{c l}$ is the clothing surface temperature, ${ }^{\circ} \mathrm{C}$.

Note: $1 \mathrm{met}=58.2 \mathrm{~W} / \mathrm{m}^{2} ; 1 \mathrm{clo}=0.155 \mathrm{~m}^{2} \mathrm{~K} / \mathrm{W}$.

In the above formulas, there are variables that have reference values, and variables that are determined by calculation according to certain formulas as well as using measuring instruments.

Data on the metabolic rate dependence on physical activity and clothing insulation coefficient for typical combinations of clothing items are given in Appendices B and C [15], respectively.

The values of the effective mechanical power $W$ and the water vapor partial pressure $p_{a}$ can be determined by the formulas in [18], and that of the mean radiant temperature can be 
determined by the formula in [19].

Indicators $t_{c l}, h_{c}$ can be determined using successive iterations according to the above formulas (2), (3). The clothing surface area factor $f_{c l}$ can be determined by Eq. (4). Air velocity $v_{a r}$, air temperature $t_{a}$, and room humidity (necessary for calculating the partial pressure) can be determined using suitable measuring devices. A more detailed description of the parameters that make up the PMV equation and the human thermoregulation system is given in [18, 19].

Since the PMV equation is comprehensive and complex, and therefore not suitable for manual calculation, there are several simplified ways to determine it:

- Using 28 Fanger's comfort diagrams [20]. These diagrams are intended for practical use. Each diagram depicts comfort lines, that is, curves through various combinations of two variables that will create comfort if the values of the other variables are kept constant. For the practical application of comfort diagrams, the activity level and clothing insulation coefficient must first be evaluated, then combinations of four indoor microclimate parameters can be found that will provide thermal comfort.

- Using the specialized application CBE Thermal Comfort Tool [21].

- Using computer programs developed based on the code in Appendix D [15] and calculation methods in Excel [18, 22].

- Using the data in Appendix E [15], which provides tables of PMV values for different combinations of activity, clothing, temperature, and relative air velocity.

- Using adequate models based on intelligent technologies.

\subsection{Data Preparation}

To calculate the PMV index in accordance with the regulations of ISO 7730:2005, one can use the calculation program proposed by the Federal State Unitary Enterprise Research Institute of Industrial and Marine Medicine of the Federal Biomedical Agency [18].

A comparative analysis of the calculation program's results with the PMV values, presented in ISO 7730:2005 Table D1. (Table 2), was performed to check its adequacy.

Input data for the calculation program were the values of indoor air temperature $\left(t_{a}\right)$, mean radiant temperature $\left(t_{r}\right)$, relative air velocity $\left(v_{a}\right)$, humidity $(p h i)$, metabolic rate $(M)$, and clothing insulation coefficient $\left(I_{c l}\right)$, from ISO 7730:2005 Table D1.

According to the comparative analysis of the calculation results given in Table 2, the adequacy of the calculation program can be estimated. After checking the adequacy of the calcu-

Table 2. Comparison of the results of the calculation program with the PMV values of the ISO 7730:2005 standard

\begin{tabular}{ccccccccc}
\hline \multirow{2}{*}{ No. } & $t_{a}\left({ }^{\circ} \mathrm{C}\right)$ & $t_{r}\left({ }^{\circ} \mathrm{C}\right)$ & $v_{a}(\mathrm{~m} / \mathrm{s})$ & $P h i(\%)$ & $M\left(\mathrm{~W} / \mathrm{m}^{2}\right)$ & $I_{c l}(\mathrm{clo})$ & \multicolumn{3}{c}{ PMV } \\
\hline 1 & 22.0 & 22.0 & 0.1 & 60 & 69.84 & 0.5 & -0.75 & Calculation program \\
\hline 2 & 27.0 & 27.0 & 0.1 & 60 & 69.84 & 0.5 & 0.77 & -0.75 \\
3 & 27.0 & 27.0 & 0.3 & 60 & 69.84 & 0.5 & 0.44 & 0.77 \\
4 & 23.5 & 25.5 & 0.1 & 60 & 69.84 & 0.5 & -0.01 & 0.43 \\
5 & 23.5 & 25.5 & 0.3 & 60 & 69.84 & 0.5 & -0.55 & -0.01 \\
6 & 19.0 & 19.0 & 0.1 & 40 & 69.84 & 1.0 & -0.60 & -0.55 \\
7 & 23.5 & 23.5 & 0.1 & 40 & 69.84 & 1.0 & 0.50 & -0.60 \\
8 & 23.5 & 23.5 & 0.3 & 40 & 69.84 & 1.0 & 0.12 & 0.36 \\
9 & 23.0 & 21.0 & 0.1 & 40 & 69.84 & 1.0 & 0.05 & 0.12 \\
10 & 23.0 & 21.0 & 0.3 & 40 & 69.84 & 1.0 & -0.16 & 0.05 \\
11 & 22.0 & 22.0 & 0.1 & 60 & 93.12 & 0.5 & 0.05 & -0.17 \\
12 & 27.0 & 27.0 & 0.1 & 60 & 93.12 & 0.5 & 1.17 & 0.05 \\
13 & 27.0 & 27.0 & 0.3 & 60 & 93.12 & 0.5 & 0.95 & 1.17 \\
\hline
\end{tabular}

Since the metabolic rate in the calculation program is presented in $\mathrm{W} / \mathrm{m} 2$, the values from ISO 7730:2005 Table D1 were also converted to W/m² 
lation program, the formulas for calculating the relative air velocity and effective mechanical power were modified:

- in accordance with [15, 23], if the metabolic rate was above 1 met, the relative air velocity was calculated using the following equation: $v_{a r}^{\prime}=v_{a r}+0.3(M-1)$.

- effective mechanical power in accordance with the formula given in [18].

To prepare the data for the development of fuzzy logic and neural network-based models, the following parameters were taken as input parameters for this program: air temperature in the room and mean radiant temperature range from $15^{\circ} \mathrm{C}-30^{\circ} \mathrm{C}$ range (with a step of $2.5^{\circ} \mathrm{C}$ ), air velocity range from $0.1-0.3 \mathrm{~m} / \mathrm{s}$ (with a step of $0.05 \mathrm{~m} / \mathrm{s}$ ), humidity range from $30 \%-60 \%$ (with a step of $10 \%$ ). Parameter values for the metabolic rate and clothing insulation coefficient were taken for office workers, and were equal to $70 \mathrm{~W} / \mathrm{m}^{2}$ (for sedentary office work) and 1 clo (corresponding to a typical office set, underwear with short sleeves and legs, shirts, trousers, jackets, socks, and shoes), respectively. The PMV index for 980 combinations of input parameters was computed using the calculation program.

\section{Results}

\subsection{Development of the Fuzzy Logic-Based Model}

Fuzzy logic and its methods have found numerous applications in modeling and control problems. When talking about fuzzy logic, most often fuzzy inference systems are meant.

There are four classical algorithms for fuzzy inference: the Mamdani, Sugeno, Tsukamoto, and Larsen algorithms. Within the framework of this article, the authors have considered the implementation of the Mamdani fuzzy inference algorithm owing to its simplicity and extensive applications. A schematic diagram of the stages of the developing model for assessing thermal comfort based on the Mamdani fuzzy inference algorithm is shown in in Figure 1

The Mamdani algorithm consists of the following stages:

- Formation of the rule base for fuzzy inference systems.

- Fuzzification of input variables.

- Aggregation of subconditions in fuzzy production rules.

- Activation of subconclusions in fuzzy production rules.

- Accumulation of conclusions in fuzzy production rules.

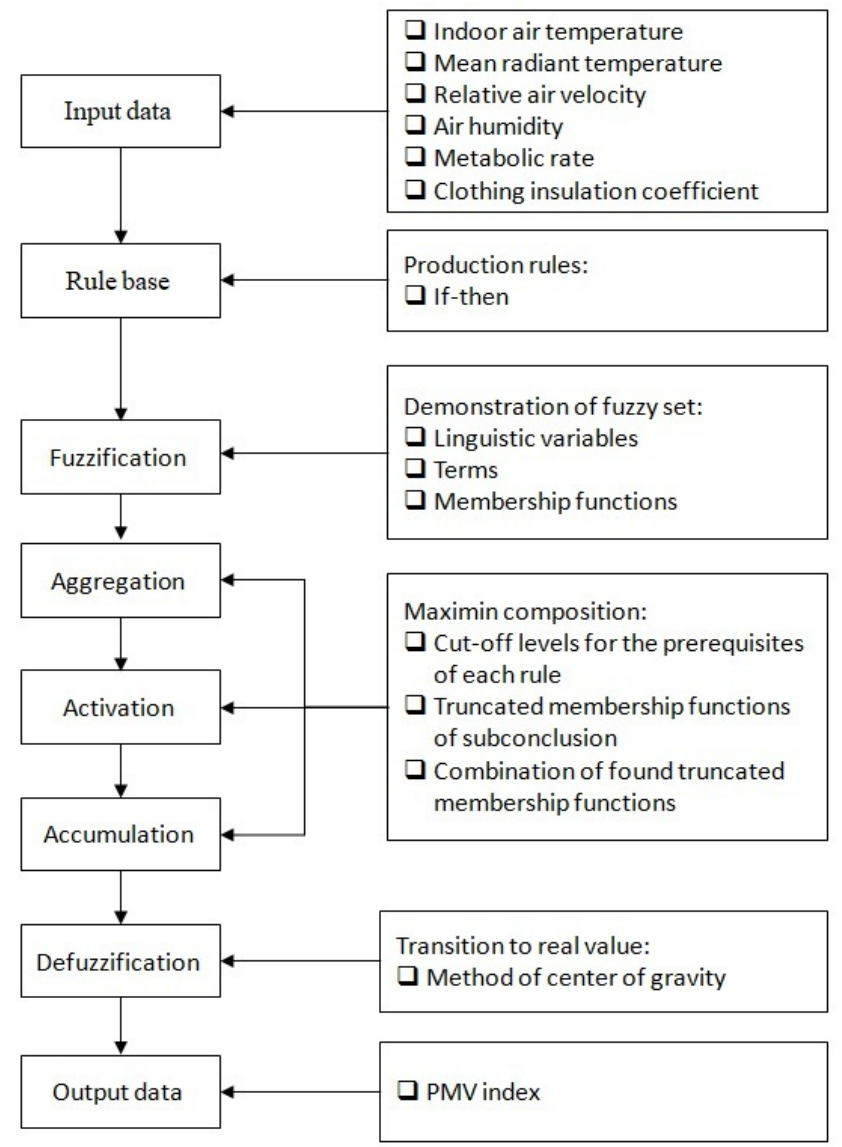

Figure 1. Schematic of the development process of the fuzzy model.

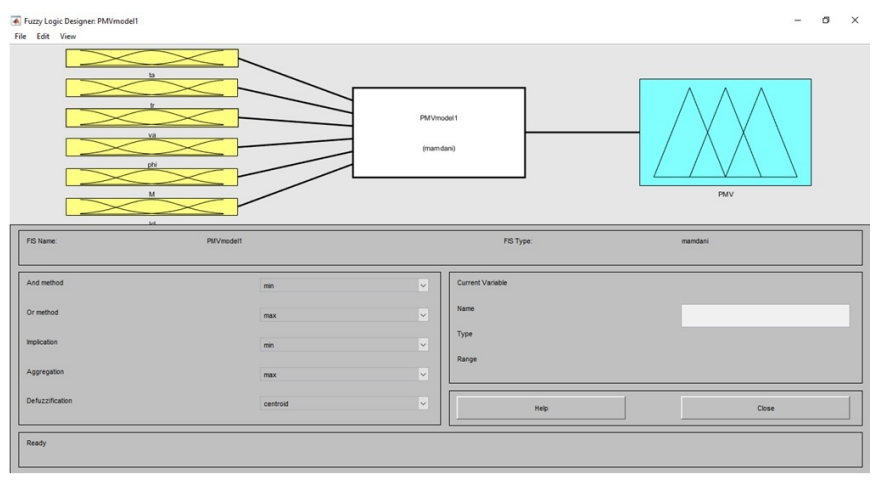

Figure 2. The structure of the developed model in the Fuzzy Logic Toolbox package.

- Defuzzification of output variables.

Rule bases of fuzzy inference systems are designed to formally represent empirical knowledge or knowledge of experts in a particular problem area. Within the framework of this study, the rules were formed based on the analysis of the dependence of the PMV index on the variation of input data (980 input combinations). To form the rule base, the ranges of 

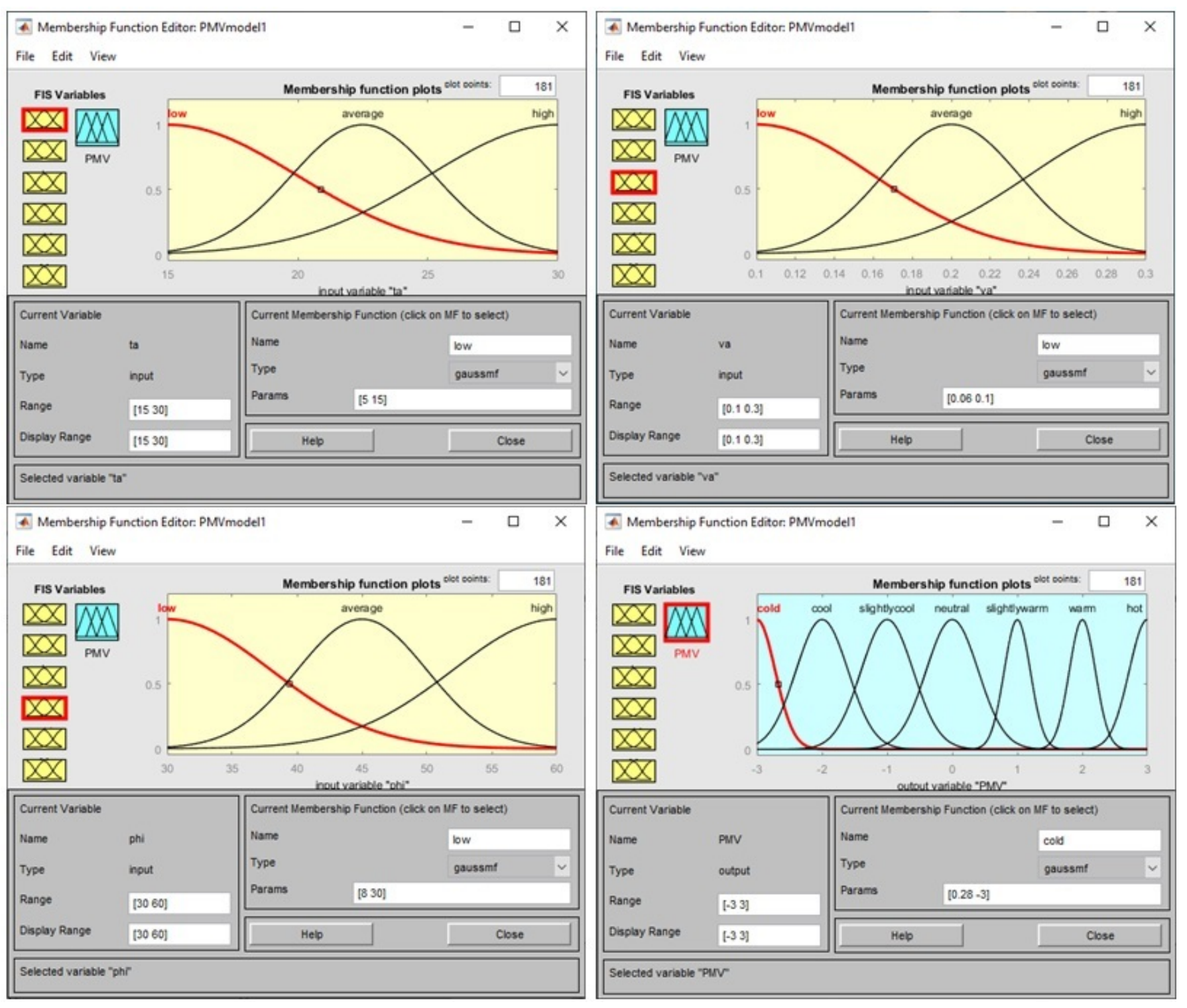

Figure 3. Fuzzification of input and output variables (the graph of the membership function of the "mean radiant temperature" is similar to the graph of the membership function of the "indoor air temperature").

the input and output parameters were divided into the following terms (Tables 3, 4 .

Since the input variables, namely "indoor air temperature", "mean radiant temperature", "relative air velocity", and "air humidity" were represented by three terms, and the indicators "metabolic rate" and "clothing insulation coefficient" were taken as constant values in this study, the total number of rules was 81. A fragment of the generated rule base is shown in Table 5 .

There is a special extension package Fuzzy Logic Toolbox, for implementing the fuzzy modeling process in the MATLAB environment. The structure of the developed model in the Fuzzy
Logic Toolbox package is shown in Figure 2

The second stage of modeling is fuzzification. Fuzzification or the introduction of fuzziness is the process of finding the membership function of fuzzy sets based on ordinary initial data. At this stage, a correspondence is established between the numerical value of the input variable of the fuzzy inference system and the value of the membership function of the corresponding linguistic variable.

There are a number of typical curve shapes for specifying membership functions. The most widespread are triangular, trapezoidal, and Gaussian membership functions. In this study, 
Table 3. Terms of input parameters

\begin{tabular}{rlccc}
\hline \multirow{2}{*}{ No. } & Input variable & \multicolumn{3}{c}{ Term name } \\
\cline { 2 - 5 } & & Low & Average & High \\
\hline \multirow{2}{*}{1} & $\begin{array}{l}\text { Indoor air } \\
\text { temperature }\left({ }^{\circ} \mathrm{C}\right)\end{array}$ & {$[15-20]$} & $(20-25]$ & $(25-30]$ \\
2 & $\begin{array}{l}\text { Mean radiant } \\
\text { temperature }\left({ }^{\circ} \mathrm{C}\right)\end{array}$ & {$[15-20]$} & $(20-25]$ & $(25-30]$ \\
3 & $\begin{array}{l}\text { Relative air } \\
\text { velocity }(\mathrm{m} / \mathrm{s})\end{array}$ & {$[0.1-0.15]$} & $(0.15-0.25]$ & $(0.25-0.3]$ \\
\hline 4 & Humidity $(\%)$ & {$[30-40]$} & $(40-50]$ & $(50-60]$ \\
\hline
\end{tabular}

Table 4. Terms of the PMV output parameter

\begin{tabular}{ccc}
\hline No. & Term name & Term range \\
\hline 1 & Hot & $(2 \div 3]$ \\
2 & Warm & $(1 \div 2]$ \\
3 & Slightly warm & $(0.5 \div 1.0]$ \\
4 & Neutral & {$[-0.5 \div 0.5]$} \\
5 & Slightly cool & $(-0.5 \div-1]$ \\
6 & Cool & $(-1 \div-2]$ \\
7 & Cold & $(-2 \div-3]$ \\
\hline
\end{tabular}

Table 5. Fragment of the formed rule base

\begin{tabular}{cccccc}
\hline $\begin{array}{c}\text { Rule } \\
\text { No. }\end{array}$ & $\begin{array}{c}\text { Indoor } \\
\text { air } \\
\text { tempera- } \\
\text { ture }\end{array}$ & $\begin{array}{c}\text { Mean } \\
\text { radiant } \\
\text { tempera- } \\
\text { ture }\end{array}$ & $\begin{array}{c}\text { Relative } \\
\text { air } \\
\text { velocity }\end{array}$ & Humidity & $\begin{array}{c}\text { PMV } \\
\text { indicator }\end{array}$ \\
\hline 1 & low & low & low & low & cool \\
2 & average & low & low & low & neutral \\
$\ldots$. & $\ldots \ldots .$. & $\ldots \ldots$. & $\ldots \ldots$. & $\ldots \ldots .$. & $\ldots \ldots .$. \\
81 & high & high & high & high & warm \\
\hline
\end{tabular}

the Gaussian membership function was chosen as the membership function. Fuzzification of input and output variables is shown in Figure 3

During the stages "Aggregation, Activation and Accumulation" the following operations were performed: first, the cut-off levels for the prerequisites of each of the rules were found; then, the truncated membership functions of the subconclusion were determined; using the max operation, the found truncated functions were combined, yielding a final fuzzy subset for the output variable.

In the last stage of fuzzy inference, the output fuzzy set is already defined, but it cannot be directly used for provid-

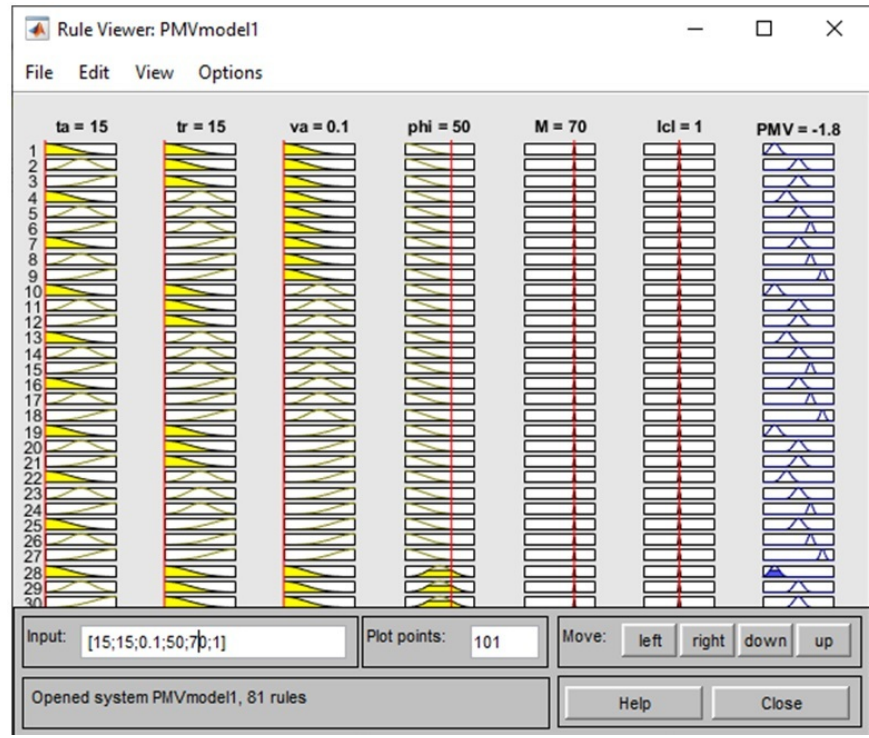

Figure 4. An example of the model's operation based on fuzzy logic.

ing the operator with accurate information or for controlling the actuator. It is necessary to make a transition from the "world of fuzzy logic" to the "real world": this stage is called defuzzification [24].

A variety of defuzzification methods can be used, but the most commonly used method calculates the "center of gravity" of a fuzzy set. Physics-wise, this method finds the center of gravity of a flat figure, limited by the coordinate axes and the graph of the membership function of a fuzzy set.

The last stages, from the aggregation stage to the defuzzification stage, are automatically implemented in the Fuzzy Logic Toolbox in a graphical manner.

An example of the model operation is shown in Figure 4 The following data were used for input: indoor air temperature $15^{\circ} \mathrm{C}$, mean radiant temperature $15^{\circ} \mathrm{C}$, relative air velocity 0.1 $\mathrm{m} / \mathrm{s}$, humidity $50 \%$. The output PMV value for this set was -1.80 , corresponding to the "cool" degree of comfort of the microclimate in the room.

The developed model was tested on all 980 input combinations (Figure 5), and the model's output was compared with the output of the calculation program (Table 6).

The results of this analysis show that for only 436 input combinations, the model's relative error is under $20 \%$. For other combinations, the relative error was above $20 \%$. Furthermore, in the fuzzification stage, we revised the membership functions of the input parameters, which did not improve the model's performance. 
Table 6. Comparison of the results obtained using the developed model with the PMV values obtained using the calculation program

\begin{tabular}{cccccccccc}
\hline \multirow{2}{*}{ No. } & $t_{a}\left({ }^{\circ} \mathrm{C}\right)$ & $t_{r}\left({ }^{\circ} \mathrm{C}\right)$ & $v_{a}(\mathrm{~m} / \mathrm{s})$ & phi $(\%)$ & $M\left(\mathrm{~W} / \mathrm{m}^{2}\right)$ & $I_{c l}(\mathrm{clo})$ & \multicolumn{3}{c}{ PMV } \\
\cline { 7 - 9 } & & & & & & & & Calculation program & Fuzzy model \\
\hline 1 & 15.0 & 15.0 & 0.1 & 30 & 70 & 1 & -1.80 & -1.84 \\
$\ldots$ & 17.5 & 15.0 & 0.1 & 30 & 70 & 1 & -1.49 & -1.42 \\
980 & 30.0 & 30.0 & 0.3 & 60 & 70 & 1 & $\ldots$ & $\ldots$ \\
\hline
\end{tabular}

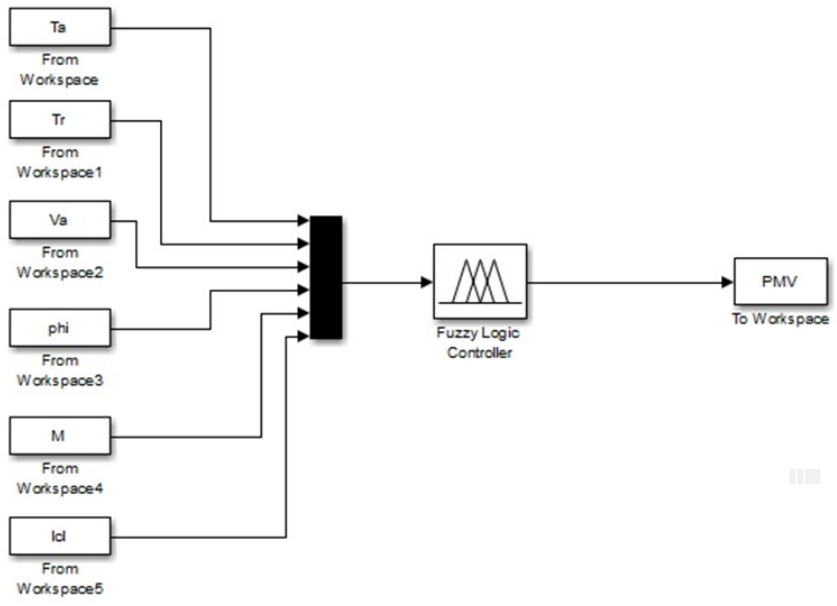

Figure 5. Schematic for calculating the PMV indicator using the developed model for 980 input combinations in the Simulink package.

\subsection{Development of the Neural Network-Based Model}

Neural networks are extremely powerful for reproducing extremely complex dependencies. Neural networks are trained using samples. The trainer of a neural network selects representative data and then runs a learning algorithm that infers the data structure [25].

The creation of the optimal structure of the mathematical model for a neural network in the MATLAB environment refers to selecting the number of network layers, the number of neurons in each layer, the network learning function, and the neuron activation function, for which the smallest error would be achieved. To solve this problem, a two-layer network is required, in which [11]:

- for the neurons of the first layer, a hyperbolic activation function is set - tansig;

- for the neurons of the second layer, a linear activation function is set - pureline.

For modeling, it was decided to select a neural network with the

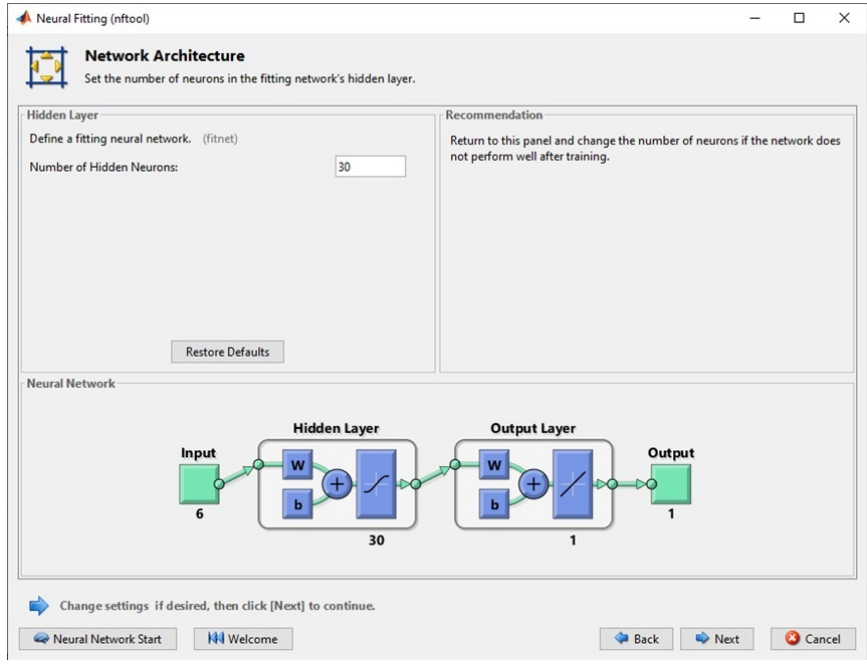

Figure 6. The structure of the neural network.

following parameters: number of neurons - 30 in the first layer and the training function trainlm (which modifies the values of weights and biases according to the Levenberg-Marquardt optimization method). This method is often used to achieve high accuracy in training a neural network. The structure of the neural network is shown in Figure 6

To train the neural network, we used the first 500 combinations of input parameters out of 980 aggregate ones, prepared before the start of the modeling process.

The magnitude of the network training error and the training duration were $10^{-10}$ and 1000 epochs, respectively (Figure 7 ).

To check the operation of the model based on neural networks, overall 980 combinations were presented as input: the 500 first input combinations used in training the network as well as the 480 subsequent input combinations that were "previously unseen" by the model (Figure 8). Further, the model's output was compared with the values obtained using the calculation program (Table 7 ).

As a result of the analysis of the obtained data, it was determined that the neural network model yielded the most accurate 
Table 7. Comparison of the results obtained using the developed model with the PMV values obtained using the calculation program

\begin{tabular}{cccccccccc}
\hline \multirow{2}{*}{ No. } & $t_{a}\left({ }^{\circ} \mathrm{C}\right)$ & $t_{r}\left({ }^{\circ} \mathrm{C}\right)$ & $v_{a}(\mathrm{~m} / \mathrm{s})$ & phi $(\%)$ & $M\left(\mathrm{~W} / \mathrm{m}^{2}\right)$ & $I_{c l}(\mathrm{clo})$ & \multicolumn{3}{c}{ PMV } \\
\cline { 7 - 9 } & & & & & & & Calculation program & Neural model \\
\hline 1 & 15.0 & 15.0 & 0.1 & 30 & 70 & 1 & -1.80 & -1.80 \\
$\ldots$ & 17.5 & 15.0 & 0.1 & 30 & 70 & 1 & -1.49 & -1.49 \\
980 & 30.0 & 30.0 & 0.3 & 60 & 70 & 1 & $\ldots$ & $\ldots$ \\
\hline
\end{tabular}

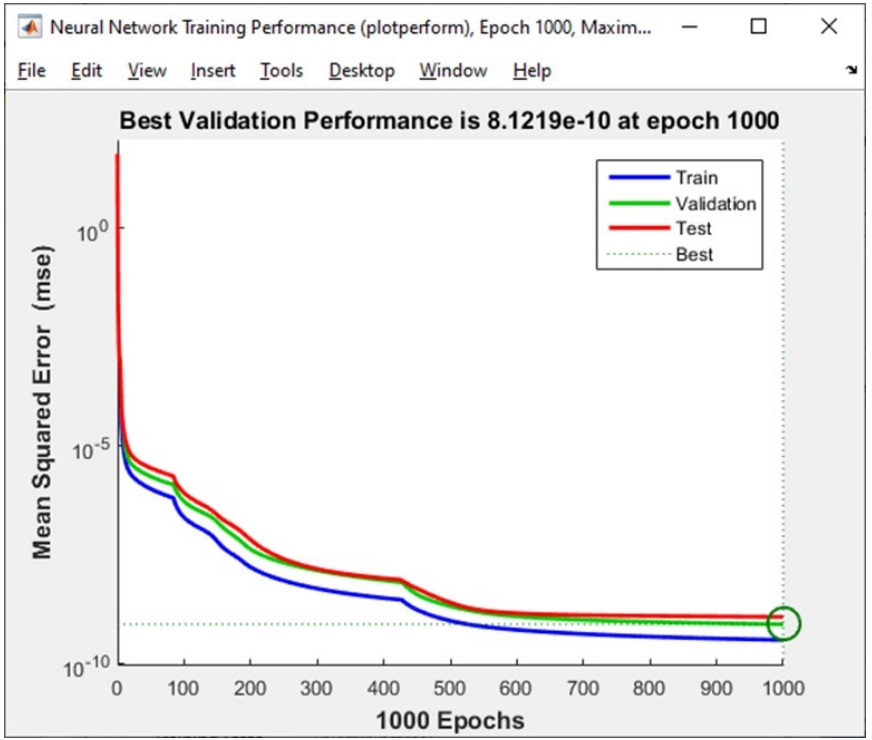

Figure 7. Graph of the neural network training error.

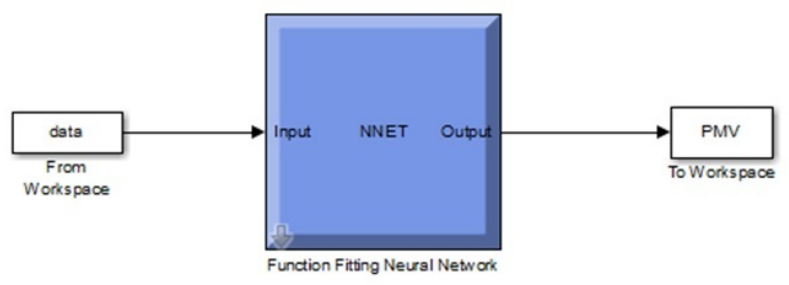

Figure 8. Schematic for calculating the PMV indicator using the developed model, for 980 input combinations, using the Simulink package.

result (error-free) for those combinations of input parameters that were used for its training. For the 598 input combinations out of the 980 submitted, the relative error was under $20 \%$.

To improve the performance of the developed model, it is necessary to extend the training set, and retrain the network on it.

\section{Discussion}

The calculation program, along with the developed models that use fuzzy logic and neural networks, enable the assessment of thermal comfort in a room, without conducting experimental studies using questionnaires or expensive control and measuring devices, which is efficient and economical. To compare the models' results with the PMV values obtained using the calculation program, the same combinations of input parameters indicated in Table D1 (columns 2-7) of ISO 7730:2005 were presented as input. The results demonstrated that the PMV index values obtained using the calculation program agreed well with the values of this parameter listed in Table D1 (column 8) for ISO 7730:2005.

Initial data were prepared for the modeling stage. Overall, 980 input combinations were formulated, using the Microsoft Excel program. Further, the PMV index was calculated using the program proposed by the researchers of the Federal State Unitary Enterprise Research Institute of Industrial and Marine Medicine of the Federal Biomedical Agency (for 980 combinations).

The prepared dataset was used during the fuzzification stage and during the stage of formulating the rule base when developing the model based on the fuzzy logic framework. Five hundred combinations from this dataset were used for training the neural network.

After the models' development, their effectiveness was assessed. During the assessment, 980 input combinations were presented as input. A comparative analysis of the model output with the output of the calculation program was performed.

Regarding the model based on fuzzy logic, only for 436 input combinations out of 980 total combinations, the relative error was under 20\%; among the presented combinations, some yielded perfect performance. For other combinations, the relative error was above $20 \%$.

The developed model based on neural networks yielded ac- 
curate results only for 500 combinations in the training set. For 598 out of the 980 overall input combinations, the relative error was under $20 \%$.

The analysis of these results showed that neural networks perform much better at assessing thermal comfort, compared with fuzzy systems. By supplementing the sample of initial data used in training the neural network, the efficiency of its operation can be increased.

\section{Conclusion}

In this study, the issues of preparing data for research and modeling were addressed. A schematic diagram of the stages of developing the model for assessing thermal comfort based on the Mamdani fuzzy inference algorithm was presented. The following research objectives, formulated in Section 2, were addressed:

- The study and description of Fanger's thermal comfort model were presented;

- Methods and software for assessing the PMV thermal comfort index were determined;

- The correctness of the calculation program was checked;

- Fuzzy logic and neural network-based models were developed;

- A comparative analysis was conducted, comparing the results obtained using the developed models with the values obtained using the calculation program.

The analysis showed that neural networks perform better in assessing thermal comfort, compared with fuzzy systems. In the future, we plan to modify the developed models to reduce the relative error and improve the models' performance.

\section{Conflict of Interest}

No potential conflict of interest relevant to this article was reported.

\section{References}

[1] M. V. Prorokova and V. V. Bukhmirov, "Energy saving and microclimate quality," Bulletin of Cherepovets State University, vol. 63, no. 2, pp. 32-35, 2015.
[2] Y. Song, S. Wu, and Y. Y. Yan, "Control strategies for indoor environment quality and energy efficiency: a review," International Journal of Low-Carbon Technologies, vol. 10, no. 3, pp. 305-312, 2015. https://doi.org/10.1093/ijlct/ ctt051

[3] A. V. Karpenko and I. Yu Petrova, "Control indoor climate," Engineering and Construction Bulletin of the Caspian Region, vol. 18, no. 4, pp. 86-95, 2016.

[4] A. V. Karpenko and I. Yu Petrova, "Indoor climate control models," Fundamental Research, vol. 7, pp. 224-229, 2016.

[5] A. I. Dounis and D. E. Manolakis, "Design of a fuzzy system for living space thermal-comfort regulation," $A p$ plied Energy, vol. 69, no. 2, pp. 119-144, 2001. https: //doi.org/10.1016/S0306-2619(00)00065-9

[6] S. S. Ahmed, M. S. Majid, H. Novia, and H. A. Rahman, "Fuzzy logic based energy saving technique for a central air conditioning system," Energy, vol. 32, no. 7, pp. 1222 1234, 2007. https://doi.org/10.1016/j.energy.2006.07.025

[7] L. Ciabattoni, G. Cimini, F. Ferracuti, G. Ippoliti, and S Longhi, "Indoor thermal comfort control based on fuzzy logic," in Advances in Chaos Theory and Intelligent Control. Cham, Switzerland: Springer, 2016, pp. 829-850. https://doi.org/10.1007/978-3-319-30340-6_35

[8] A. B. Altayeva, B. S. Omarov, and Y. I. Cho, "Intelligent microclimate control system based on IoT," International Journal of Fuzzy Logic and Intelligent Systems, vol. 16, no. 4, pp. 254-261, 2016. https://doi.org/10.5391/IJFIS. 2016.16.4.254

[9] P. M. Ferreira, A. E. Ruano, S. Silva, and E. Z. E. Conceicao, "Neural network-based predictive control for thermal comfort and energy savings in public buildings," Energy and Buildings, vol. 55, pp. 238-251, 2012. https: //doi.org/10.1016/j.enbuild.2012.08.002

[10] A. A. Argiriou, I. Bellas-Velidis, and C. A. Balaras, "Development of a neural network heating controller for solar buildings," Neural Networks, vol. 13, no. 7, pp. 811-820, 2000. https://doi.org/10.1016/S0893-6080(00)00057-5

[11] A. V. Karpenko and A.V. Glebov, "Estimation of thermal comfort using an artificial neural network," in Proceedings of 6th International Scientific Forum of Young Scientists, 
Students and Schoolchildren, Astrakhan, Russia, 2017, pp.111-115.

[12] S. Atthajariyakul and T. Leephakpreeda, "Neural computing thermal comfort index for HVAC systems," Energy Conversion and Management, vol. 46, no. 15-16, pp. 2553 2565, 2005. https://doi.org/10.1016/j.enconman.2004.12. 007

[13] H. Feriadi and W. N. Hien, "Modelling thermal comfort for tropics using fuzzy logic," in Proceedings of 8th International IBPSA Conference, Eindhoven, The Netherlands, 2003, pp. 323-330.

[14] L. P. Bilgaeva and K. G. Vlasov, "The study of models of neural network forecasting in MATLAB," in Proceedings of All-Russian Scientific and Practical Conference, Magnitogorsk, Russia, 2017, pp. 11-19.

[15] Ergonomics of the thermal environment - Analytical determination and interpretation of thermal comfort using calculation of the PMV and PPD indices and local thermal comfort criteria, ISO 7730:2005, 2005.

[16] P. O. Fanger, "Calculation of thermal comfort: introduction of a basic comfort equation," ASHRAE Transactions, vol. 73, no. 2, pp. 1-20, 1967.

[17] P. O. Fanger, H. Melikov, H. Hanzawa, and J. Ring, "Air turbulence and sensation of draught," Energy and Buildings, vol. 12, no. 1, pp. 21-39, 1988. https://doi.org/10. 1016/0378-7788(88)90053-9

[18] T. Ryabova, A. Sulin, and A. Nikitin, Thermal Comfort Indices. Saint Petersburg, Russia: ITMO University, 2016.

[19] B. W. Olesen, "Thermal comfort," Technical Review, vol. 2, pp. 3-37, 1982.

[20] P. O. Fanger, Thermal Comfort. New York, NY: McGrawHill, 1973.

[21] F. Tartarini, S. Schiavon, T. Cheung, and T. Hoyt, "CBE Thermal Comfort Tool: online tool for thermal comfort calculations and visualizations," SoftwareX, vol. 12, article no. 100563, 2020. https://doi.org/10.1016/j.softx.2020. 100563

[22] M. C. G. da Silva, "Spreadsheets for calculation of thermal comfort indices PMV and PPD," University of Coimbra, Portugal, 2014.
[23] Thermal Environmental Conditions for Human Occupancy, ANSI/ASHRAE Standard 55-2017, 2017.

[24] Technical Collection Schneider Electric, vol. 31, 32, 2009.

[25] E. S. Aldoshkina, A. D. Kuznetsov, A. A. Pugachev, O. S. Seroukhova, T. E. Simakina, and V. V. Chukin, "The experience of using the apparatus of neural networks for analysis and forecasting the time series of air temperature," Scientific notes of the Russian State Hydrometeorological University, no. 11, pp. 91-100, 2009.

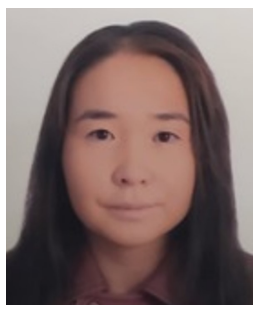

L. Zh. Sansyzbay is a Ph.D. candidate at the Department of System Analysis and Control, L.N. Gumilyov Eurasian National University, Nur-Sultan, Kazakhstan. In the master's program, the subject of her research was the introduction of intelligent technologies to maintain a favorable indoor microclimate. She has over 20 publications, including four papers in indexed foreign journals in the direction of the research project.

E-mail : sansyzbaylazzat@gmail.com

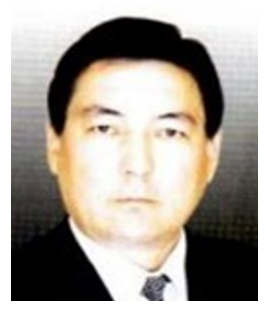

B. B. Orazbayev is a doctor of technical science, professor at the Department of System Analysis and Control, L.N. Gumilyov Eurasian National University, NurSultan, Kazakhstan. He has more than 580 publications, including 22 monographs and 27 works in indexed foreign journals. He led to several state budgets, contractual research, and scientific projects for the development of models, optimization, and control of process facilities. He proposed new classes of decision-making problems and a set of methods for their solutions, and proposed a methodology for creating intelligent decision-making systems. Seventeen Ph.D. and doctoral theses have been successfully defended under his supervision.

E-mail : batyr_o@mail.ru

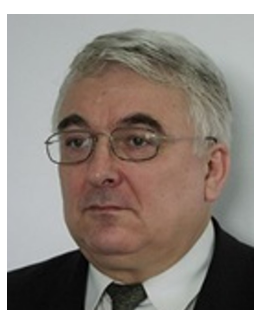

W. Wójcik is a Ph.D. professor and the Head of the Institute of Electronics and Information Technology, Lublin University of Technology (Poland). He is a member of the specialized scientific councils of Lublin University of Technology, and D.Serikbayev East Kazakhstan State Technical University, a 
member of the editorial board of scientific journals "Energetics"

(Belarus), "Physics and Chemistry of Solid State" (Ukraine), "Electronics" (Ukraine), and "Informatyka, Automatyka, Pomiary w Gospodarce i Ochronie Środowiska" (Poland), a member of the Ukrainian Academy of Informatics, Lublin Scientific Society, Chairman of the Supervisory Board of the Lublin Sci- ence $\&$ Technology Park Center of Innovation and Technology Transfer. He has published over 410 works, including 56 monographs, over 350 articles, and five patents. He has prepared 15 doctors of sciences and is the thesis advisor for 10 candidates. E-mail : waldemar.wojcik@pollub.pl 